\title{
Amyloidogenic Potential of $\alpha$-Chymotrypsin in Different Conformational States
}

Nasrollah Rezaei-Ghaleh,, ${ }^{1,2}$ Markus Zweckstetter, ${ }^{1,3}$ Dina Morshedi, ${ }^{2,4}$

Azadeh Ebrahim-Habibi, ${ }^{2,5}$ Mohsen Nemat-Gorgani ${ }^{2,6}$

${ }^{1}$ Department for NMR-based Structural Biology, Max-Planck-Institute for Biophysical Chemistry, Göttingen, Germany

${ }^{2}$ Institute of Biochemistry and Biophysics, University of Tehran, Iran

${ }^{3}$ DFG Research Center for the Molecular Physiology of the Brain, Göttingen, Germany

${ }^{4}$ Industrial and Environmental Biotechnology Department, National Institute

of Genetic Engineering and Biotechnology, Tehran, Iran

${ }^{5}$ Biology Group, School of Basic Sciences, Science and Research Branch,

Islamic Azad University, Hesarak, Tehran, Iran

${ }^{6}$ Stanford Genome Technology Center, Stanford University, Palo Alto, CA

Received 13 February 2008; revised 19 August 2008; accepted 19 August 2008

Published online 2 September 2008 in Wiley InterScience (www.interscience.wiley.com). DOI 10.1002/bip.21079

\section{ABSTRACT:}

Amyloid fibril formation is widely believed to be a generic property of polypeptide chains. In the present study, $\alpha-$ chymotrypsin, a well-known serine protease has been driven toward these structures by the use of two different conditions involving (I) high temperature, $\mathrm{pH} 2.5$, and (II) low concentration of trifluoroethanol (TFE), pH 2.5. A variety of experimental methods, including fluorescence emission, dynamic quenching, steady-state fluorescence anisotropy, far-UV circular dichroism, nuclear magnetic resonance spectroscopy, and dynamic light scattering were employed to characterize the conformational states of $\alpha$ chymotrypsin that precede formation of amyloid fibrils. The structure formed under Condition I was an unfolded monomer, whereas an $\alpha$-helical rich oligomer was induced in Condition II. Both the amyloid aggregationprone species manifested a higher solvent exposure of

Correspondence to: Markus Zweckstetter; e-mail: mzwecks@gwdg.de or Mohsen Nemat-Gorgani; e-mail: mohsenn@stanford.edu

Contract grant sponsor: DFG

Contract grant numbers: ZW 71/2-1, 3-1

Contract grant sponsors: Max Planck Society, Research Council of the University of Tehran, Iranian National Science Foundation (INSF)

(C) 2008 Wiley Periodicals, Inc. hydrophobic and aromatic residues compared with the native state. Upon incubation of the protein in these conditions for $48 \mathrm{~h}$, amyloid-like fibrils were formed with diameters of about 10-12 nm. In contrast, at neutral $\mathrm{pH}$ and low concentration of TFE, a significant degree of amorphous aggregation was observed, suggesting that charge neutralization of acidic residues in the amyloid core region has a positive influence on amyloid fibril formation. In summary, results presented in this communication suggest that amyloid fibrils of $\alpha$-chymotrypsin may be obtained from a variety of structurally distinct conformational ensembles highlighting the critical importance of protein evolution mechanisms related to prevention of protein misfolding. (C) 2008 Wiley Periodicals, Inc. Biopolymers 91: 28-36, 2009. Keywords: amyloid-like fibril; protein aggregation; $\alpha$-chymotrypsin; trifluoroethanol

This article was originally published online as an accepted preprint. The "Published Online" date corresponds to the preprint version. You can request a copy of the preprint by emailing the Biopolymers editorial office at biopolymers@wiley.com 


\section{INTRODUCTION}

myloid or amyloid-like fibrils are elongated, unbranched protein fibrils with diameters ranging from 5 to $14 \mathrm{~nm}$, which show a characteristic cross$\beta$ pattern in X-ray fiber diffraction studies. ${ }^{1}$ It is well-established that protein misfolding followed by aggregation into amyloid fibrils may lead to a group of pathologic states known as amyloid diseases, including Alzheimer's, Parkinson's and Huntington's diseases, transmissible spongiform encephalopathies, and systemic amyloidoses. ${ }^{2,3}$ Furthermore, amyloid fibrils have been proven useful as templates for constructing nanometer-scale structures. ${ }^{4,5}$

Various experimental conditions have been successfully employed to drive a variety of proteins toward amyloid aggregation in vitro, ${ }^{6,7}$ suggesting that formation of amyloid fibrils is a generic property of polypeptide chains. ${ }^{6}$ Based on these studies, three molecular models have been proposed for formation of amyloid fibrils: (i) the "refolding" model, in which a large fraction of the protein backbone differs in conformation between the native and fibrillar form; (ii) the "gain-of-interaction" model, where only a small portion of the protein differs in conformation between the native and the fibrillar form; and (iii) the "natively disordered" model, in which amyloid fibrils are composed of protein sequences or sequence fragments that are natively unfolded.,

Although completely or partially unfolded conformations may be especially prone to amyloid fibrillation, the fully folded states of polypeptides may also demonstrate a propensity to initiate aggregation, ${ }^{10,11}$ even in the absence of nativestate destabilization. ${ }^{11}$ Amyloid fibril formation may also proceed from different conformations of partially unfolded proteins, ${ }^{12-17}$ although the essential nature of the resulting amyloid fibrils can be largely independent of the conformational properties of the soluble precursors. ${ }^{12}$ To obtain insight into the molecular mechanism of amyloid fibrillation and develop potential intervention strategies, great interest exists in the properties of the conformational states populated under conditions where the proteins are driven toward amyloid aggregation. ${ }^{7,18,19}$

$\alpha$-Chymotrypsin is a well-known serine protease with three chains connected by five interchain and intrachain disulfide bonds (see Figure 1). In its native state, it folds into two antiparallel $\beta$-barrel domains. Both the six-stranded antiparallel $\beta$-barrels consist of a Greek key motif followed by an antiparallel hairpin motif. ${ }^{20}$ Although the native state of this all- $\beta$ protein probably benefits a negative design to prevent its assembly through intermolecular $\beta$-sheets, ${ }^{21}$ a partially structured intermediate state of $\alpha$-chymotrypsin, induced by the fluorinated alcohol trifluoroethanol (TFE), has been reported to generate amyloid fibrils. ${ }^{22,23}$ However,

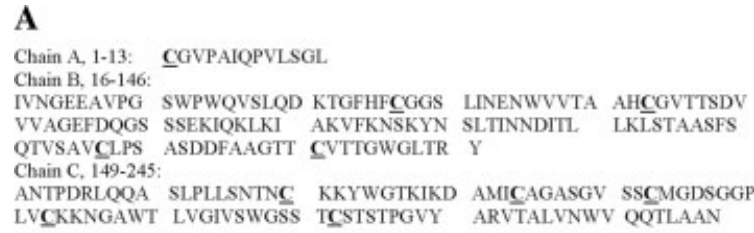

$\mathbf{A}$

\section{B}

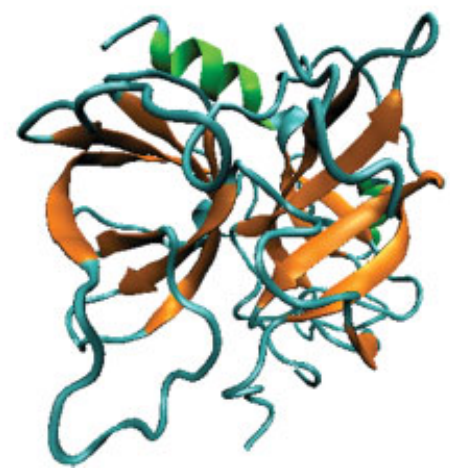

FIGURE 1 (A) Primary structure of $\alpha$-chymotrypsin (bovine). All 10 cysteine residues of the protein (underlined) form disulfide bonds, as follows: C1-C122, C42-C58, C136-C201, C168-C182, and 191-220. (B) Ribbon representation of the three-dimensional structure of $\alpha$-chymotrypsin (PDB: 2CHA).

this amyloidogenic behavior was found to be accompanied by a high degree of amorphous aggregation, as reflected in significant turbidity of the protein solution and transmission electron microscopy (TEM) images. ${ }^{22,23}$

In the present study, two different experimental conditions were employed to form amyloid-like fibrils from $\alpha$-chymotrypsin, with low levels of amorphous aggregates. Using a battery of different biophysical techniques, we show that the conformations present in the two conditions at the beginning of aggregation are largely different, that is a thermally induced unfolded monomer and TFE-induced $\alpha$-helical oligomers.

\section{RESULTS}

\section{Chymotrypsin Forms Amyloid-Like Fibrils}

Thioflavin T (ThT) is widely used as a marker of amyloid fibril formation in vitro, manifesting a dramatic increase in fluorescence intensity in the presence of amyloid or amyloidlike fibrils. ${ }^{24}$ Figure $2 \mathrm{~A}$ shows emission spectra of ThT, before and after addition of $\alpha$-chymotrypsin preincubated for $48 \mathrm{~h}$ at an acidic $\mathrm{pH}(2.5)$ either $57^{\circ} \mathrm{C}$ (Condition I) or $12.5 \%$ TFE (Condition II). At the end of the incubation period, ThT fluorescence was substantially enhanced. Furthermore, $\alpha$-chymotrypsin aggregated in the two conditions showed a significant enhancement and red shift of the absorbance 

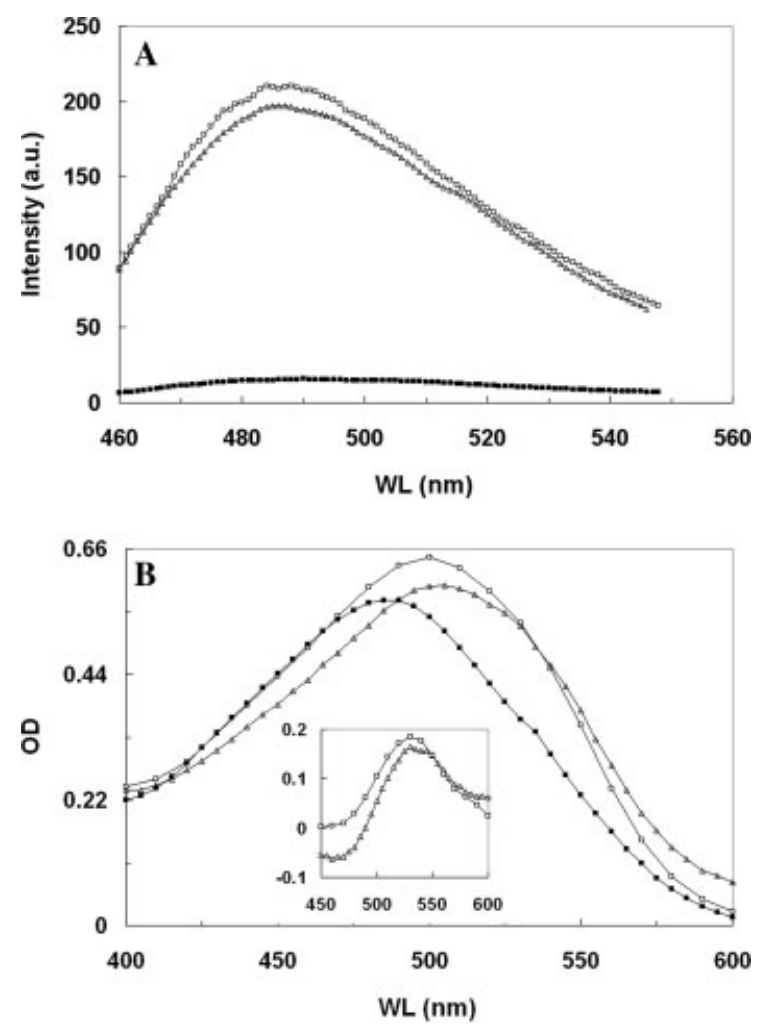

FIGURE 2 (A) Thioflavin T (ThT) fluorescence emission spectrum before ( $\mathbf{\square})$ and after addition of $\alpha$-chymotrypsin preincubated for $48 \mathrm{~h}$ at $\mathrm{pH} 2.5$ and either $57^{\circ} \mathrm{C}(\square)$ or $12.5 \%$ TFE $(\triangle)$. The excitation wavelength was $440 \mathrm{~nm}$. (B) Congo red absorbance spectra before ( $\square$ ) and after addition of $\alpha$-chymotrypsin preincubated for $48 \mathrm{~h}$ at $\mathrm{pH} 2.5$ and either $57^{\circ} \mathrm{C}(\square)$ or $12.5 \%$ TFE $(\triangle)$. The difference spectra are shown in the Inset.

spectrum of the amyloid-sensitive dye Congo red (Figure 2B). The absorbance difference spectrum manifested a clear peak at about $530-535 \mathrm{~nm}$, indicative of the formation of amyloid fibrils. Formation of these structures is further supported by transmission electron micrographs (see Figure 3). After $48 \mathrm{~h}$ of incubation, long straight fibrils were observed with a diameter of about $10-12 \mathrm{~nm}$, similar to the width of the fibrillar structures formed by other amyloidogenic proteins. ${ }^{25}$ Noteworthy, amyloid fibrils were also formed in the presence of phenylmethylsulfonyl fluoride (PMSF) (data not shown), excluding an influence of autolysis.

The conformational changes occurring during aggregation were further probed by far-UV circular dichroism (CD). Native $\alpha$-chymotrypsin showed global and local minima around 204 and $230 \mathrm{~nm}$ (see Figure 4), respectively, in agreement with its 3D structure. After $48 \mathrm{~h}$ of incubation in Conditions I and II, the CD spectra were strongly changed and displayed wide negative peaks around 216-218 nm, suggestive of the existence of extended intermolecular $\beta$-conformation. ${ }^{22}$ The combined data demonstrate that $\alpha$-chymotrypsin forms amyloid fibrils when incubated in the two different conditions.

\section{Hydrophobic Exposure of the Conformations at the Beginning of Aggregation}

To study the conformational properties of the precursors to amyloid fibrils, we used a variety of different biophysical methods. Fluorescence emission spectra were measured by excitation at 295 and $280 \mathrm{~nm}$ (data not shown) immediately after subjecting $\alpha$-chymotrypsin to the two conditions. At $\mathrm{pH} 2.5$, the fluorescence intensity was slightly lower than that observed at $\mathrm{pH}$ 7.0. Subsequent increase of the temperature to $57^{\circ} \mathrm{C}$ or addition of $12.5 \%$ TFE resulted in a prominent

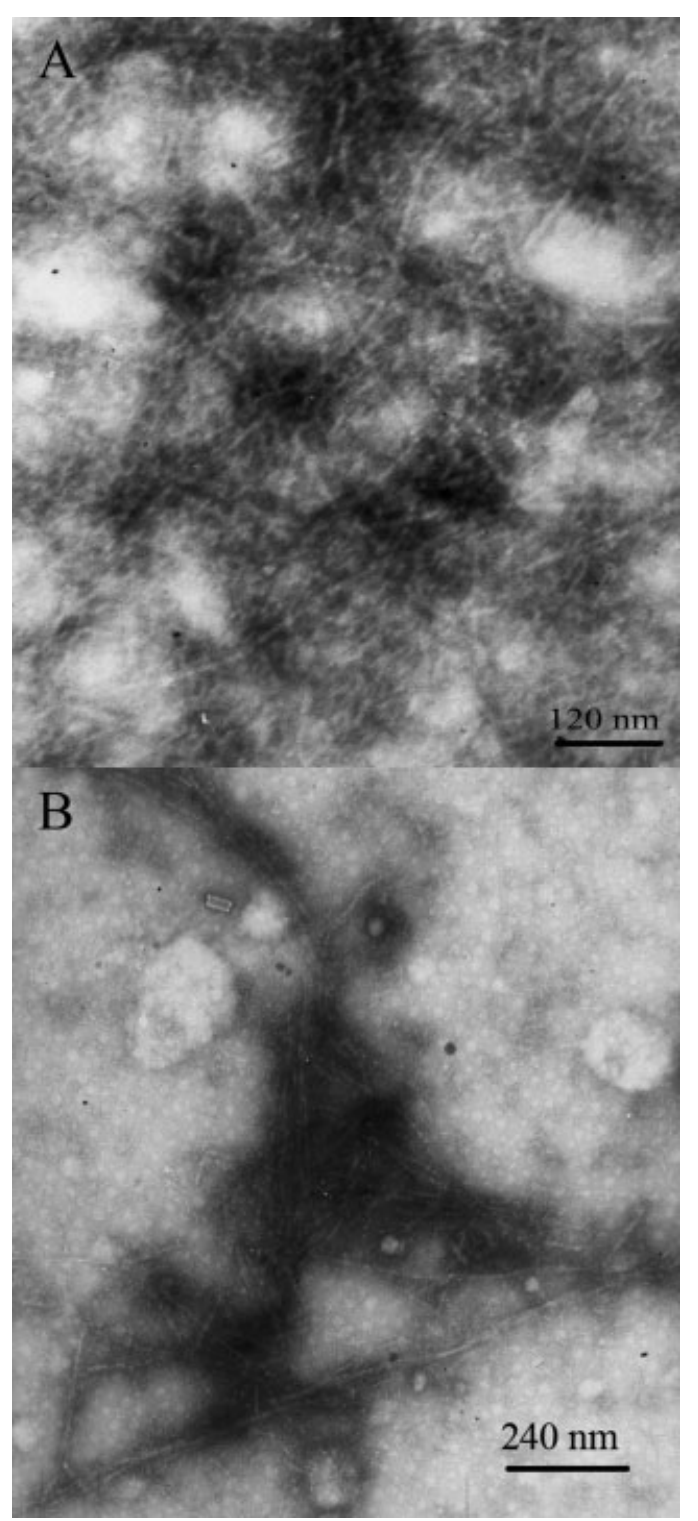

FIGURE 3 TEM image of $\alpha$-chymotrypsin incubated for $48 \mathrm{~h}$ at pH 2.5 and either $57^{\circ} \mathrm{C}$ (A) or $12.5 \%$ TFE (B). 


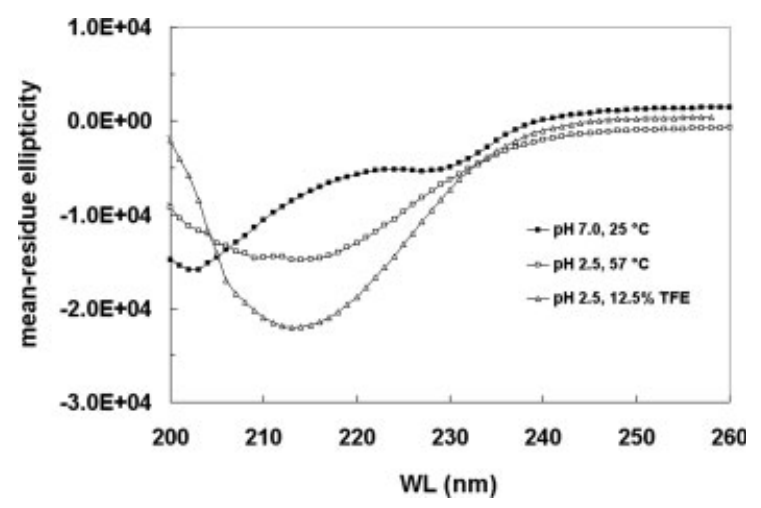

FIGURE 4 Far-UV CD spectra of native $\alpha$-chymotrypsin ( $\square$ ) and $\alpha$-chymotrypsin preincubated for $48 \mathrm{~h}$ at $\mathrm{pH} 2.5$ and either $57^{\circ} \mathrm{C}$ $(\square)$ or $12.5 \% \operatorname{TFE}(\triangle)$. The unit of the $y$-axis is degree $\mathrm{cm}^{2}$ $\mathrm{dmol}^{-1}$.

decrease in fluorescence intensity (Figure 5A). In addition, the wavelength of maximal emission intensity was shifted from $335 \mathrm{~nm}$ in the native condition $\left(\mathrm{pH} 7.0,25^{\circ} \mathrm{C}\right)$ to 351 $\mathrm{nm}$ in Conditions I and II. The fully unfolded form of $\alpha$ chymotrypsin obtained by addition of $8 M$ urea peaked at 356 $\mathrm{nm}$. These observations suggest that at least some of the eight tryptophan residues buried in the native state, become exposed to the solvent when $\alpha$-chymotrypsin is exposed to the amyloid-favoring Conditions I and II.

Increased hydrophobic exposure is also supported by the polarity-sensitive probe 1-anillino-8-naphthalene sulfonate (ANS). At pH 2.5 and $25^{\circ} \mathrm{C}$, the emission spectrum of ANS showed a slight increase in intensity and a blue shift upon protein addition, when compared to the spectrum observed at $\mathrm{pH}$ 7.0. These changes, however, were much stronger when the temperature was raised or TFE was added, that is, when either of the Conditions I or II was induced (Figure 5B). It is interesting to note that the maximal intensity of ANS emission increased during the first hour of incubation in both Conditions I and II. This may indicate that the protein molecules expose exceedingly larger hydrophobic areas during the early events of amyloid fibril formation.

To further examine the solvent accessible surface characteristics of the protein species induced in the amyloidgenic Conditions I and II, dynamic quenching study with the neutral quencher acrylamide was performed (Table I). The Stern-Volmer constant, $K_{\mathrm{SV}}$, obtained from such studies is equal to $k_{\mathrm{q}} \cdot \tau_{0}$, where $\tau_{0}$ is the fluorescence lifetime in the absence of quencher and $k_{\mathrm{q}}$ is a bimolecular quenching constant that depends on the quencher-accessibility of protein fluorophores. ${ }^{26}$ The $F_{0} / F$ of native chymotrypsin showed a typical linear relationship with $[Q]$ with a $K_{\mathrm{SV}}$ of $1.5 \pm$ $0.0 M^{-1}$, consistent with the relatively homogeneous burial of tryptophans in the native state. At acidic $\mathrm{pH}$ and high tem-
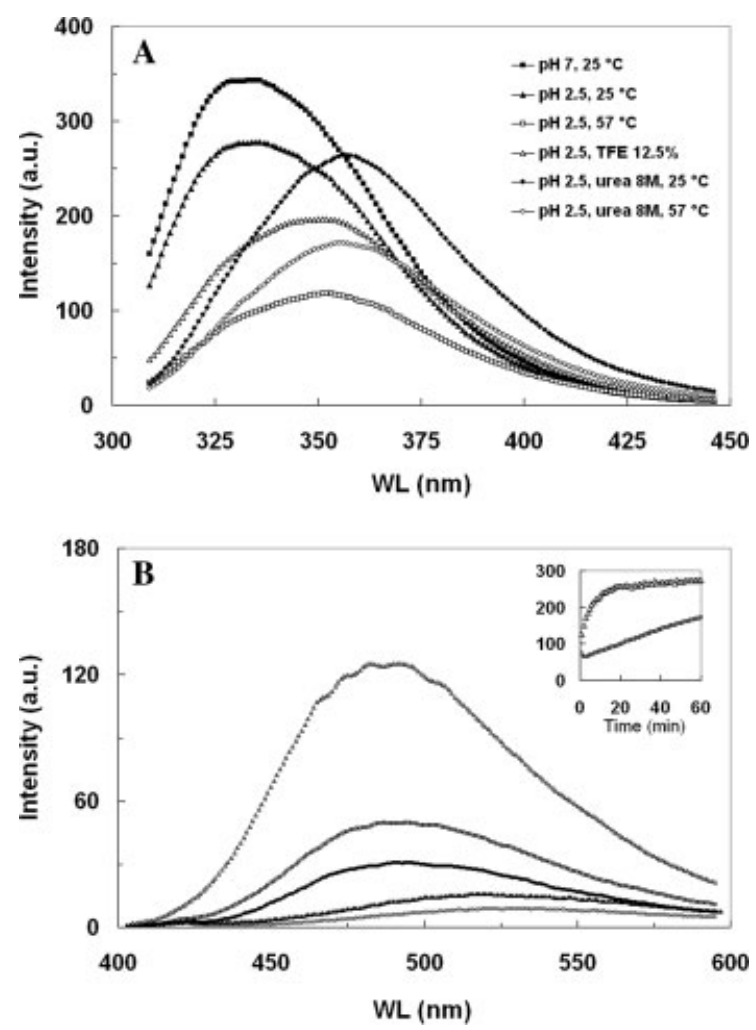

FIGURE 5 (A) Fluorescence emission spectrum of $\alpha$-chymotrypsin, at various conditions. The excitation wavelength was $295 \mathrm{~nm}$. (B) Changes in the ANS emission spectra 1 min after addition of $\alpha$ chymotrypsin. $\left(\bigcirc: \mathrm{pH} 2.5,25^{\circ} \mathrm{C}\right.$, without protein; $\mathbf{\square}: \mathrm{pH} 2.5,25^{\circ} \mathrm{C}$, with protein; $\square$ : $\mathrm{pH} 2.5,57^{\circ} \mathrm{C}$, with protein; $\mathbf{\Delta}$ : $\mathrm{pH} 2.5,12.5 \% \mathrm{TFE}$, without protein, $\triangle: \mathrm{pH} 2.5,12.5 \%$ TFE, with protein). The Inset demonstrates the gradual rising trend of ANS maximal emission intensity following addition of $\alpha$-chymotrypsin at $\mathrm{pH} 2.5$ and either $57^{\circ} \mathrm{C}(\square)$ or $12.5 \%$ TFE $(\triangle)$. The excitation wavelength was $365 \mathrm{~nm}$.

perature (Condition I), the linear relationship was preserved and $K_{\mathrm{SV}}$ increased to $7.9 \pm 0.0 M^{-1}$, significantly higher than the native state and comparable to the value obtained for the completely unfolded protein at $8 M$ urea and high temperature $\left(10.6 \pm 0.1 M^{-1}\right)$. On the other hand, at acidic $\mathrm{pH}$ and low TFE concentration (Condition II), the $F_{0} / F$ vs. $[Q]$ plot

Table I Stern-Volmer Constant $\left(K_{\mathrm{SV}}\right)$, Steady-State Anisotropy $(r)$, and Hydrodynamic Radius $\left(R_{h}\right)$ of $\alpha$-Chymotrypsin, Obtained at Various Conditions

\begin{tabular}{lrcc}
\hline & $K_{\mathrm{SV}}\left(\mathrm{M}^{-1}\right)$ & $r$ & $R_{\mathrm{h}}(\mathrm{nm})$ \\
\hline pH 7.0, 25 $5^{\circ} \mathrm{C}$ & $1.5 \pm 0.0$ & $0.09 \pm 0.00$ & $2.5 \pm 0.0$ \\
pH 2.5, 25 C & $1.5 \pm 0.0$ & $0.08 \pm 0.00$ & $2.5 \pm 0.2$ \\
pH 2.5, 57 ${ }^{\circ} \mathrm{C}$ & $7.9 \pm 0.0$ & $0.08 \pm 0.00$ & $3.3 \pm 0.5$ \\
pH 2.5, 57 ${ }^{\circ} \mathrm{C}, 8 M$ urea & $10.6 \pm 0.1$ & $0.05 \pm 0.00$ & $3.3 \pm 0.3$ \\
pH 2.5, 25 $\mathrm{C}, 12.5 \% \mathrm{TFE}$ & $18.0 \pm 0.5$ & $0.12 \pm 0.00$ & $3.3 \pm 0.3$ \\
pH 2.5, 25 $5^{\circ} \mathrm{C}, 8 \mathrm{M}$ urea & $8.0 \pm 0.2$ & $0.05 \pm 0.00$ & $4.6 \pm 0.5$ \\
\hline
\end{tabular}


manifested an obvious deviation from linearity, suggesting the possibility for some tryptophan residues being less solvent accessible than others. However, the average $K_{\mathrm{Sv}}$ value was remarkably high $\left(18.0 \pm 0.5 M^{-1}\right)$, more than twice the value obtained for the completely unfolded protein at $8 \mathrm{M}$ urea at the same temperature $\left(8.0 \pm 0.2 M^{-1}\right)$. This unexpectedly high $K_{\mathrm{SV}}$ value may be originated from a prominently longer fluorescence lifetime in the presence of TFE.

\section{Oligomerization State of the Amyloid Precursors}

Steady-state fluorescence anisotropy of proteins, $r$, is a measure of the rotational freedom of their fluorophores. Table I provides the measured fluorescence anisotropies of $\alpha$-chymotrypsin in different conditions. Although $r$ was $0.09 \pm 0.00$ for the native $\alpha$-chymotrypsin, the observed values were $0.08 \pm$ 0.00 and $0.12 \pm 0.00$ for Conditions I and II, respectively. The lower $r$ of chymotrypsin in Condition I suggests that the tryptophan residues experience a higher rotational freedom than in the native condition, although they are still more restricted than in the presence of $8 M$ urea (with $r$ of $0.05 \pm 0.00$ ). On the other hand, the remarkably high value of $r$ in Condition II (presence of $12.5 \%$ TFE) could originate from a lower rotational freedom, a shorter fluorescence lifetime, or formation of oligomeric structures. The rotational freedom of the protein fluorophores in Condition II is most likely not lower than that enjoyed by the highly compact native state of $\alpha$-chymotrypsin. Also, a shorter fluorescence lifetime is not consistent with $K_{\mathrm{SV}}$ data (see above). Thus, fluorescence anisotropy suggests the formation of oligomers of chymotrypsin in the presence of TFE.

To obtain a more direct insight into the oligomerization behavior of $\alpha$-chymotrypsin in Conditions I and II, we used dynamic light scattering. The hydrodynamic radius $\left(R_{\mathrm{h}}\right)$ of native $\alpha$-chymotrypsin was $2.5 \pm 0.0 \mathrm{~nm}$, in good agreement with that predicted on the basis of its crystal structure, ${ }^{20,27}$ or the number of residues ${ }^{28}$ (Table I). Upon addition of $8 M$ urea, $R_{\mathrm{h}}$ was increased to $3.3 \pm 0.3 \mathrm{~nm}$ (at both 25 and $57^{\circ} \mathrm{C}$ ). This value is significantly lower than that predicted for a fully unfolded protein on the basis of its number of residues (5.1 $\mathrm{nm}),{ }^{29}$ but is in agreement with the presence of five disulfide bonds. At $\mathrm{pH} 2.5$ and high temperature (Condition I), an $R_{\mathrm{h}}$ value of $3.3 \pm 0.5 \mathrm{~nm}$ was observed, suggesting that $\alpha$-chymotrypsin adopts a largely unfolded conformation. In contrast, an $R_{\mathrm{h}}$ value of $4.6 \pm 0.5 \mathrm{~nm}$ was observed in Condition II $(\mathrm{pH}$ 2.5 and $12.5 \%$ TFE), demonstrating the formation of oligomeric structures.

\section{Secondary Structure of the Conformations at the Beginning of Aggregation}

The ${ }^{1} \mathrm{H}$-NMR spectrum of native $\alpha$-chymotrypsin shows the characteristic signature of a folded protein (see Figure 6),

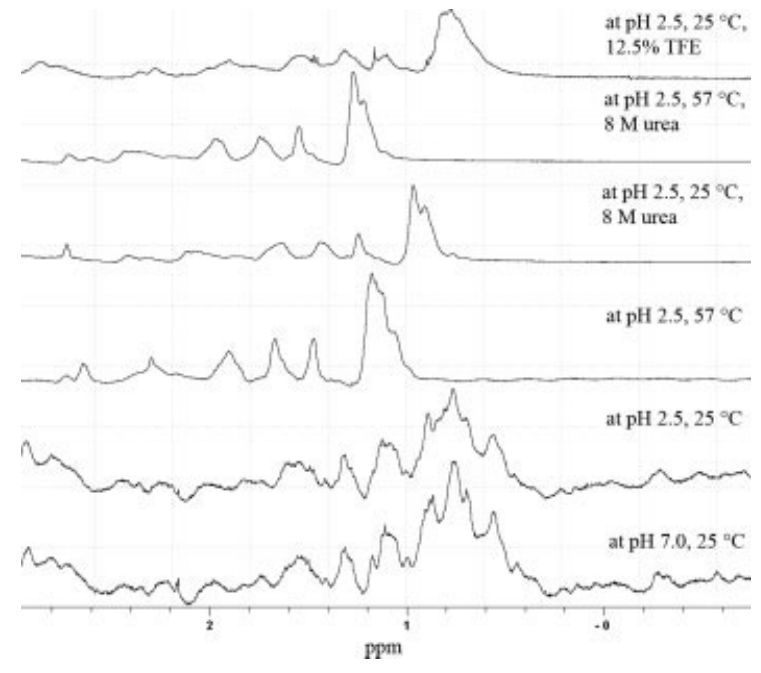

FIGURE $6 \quad{ }^{1} \mathrm{H}$-NMR spectra of $\alpha$-chymotrypsin. From bottom to top: at pH 7 and $25^{\circ} \mathrm{C}$; $\mathrm{pH} 2.5$ and $25^{\circ} \mathrm{C}$; $\mathrm{pH} 2.5$ and $57^{\circ} \mathrm{C}$; $\mathrm{pH} 2.5$, $8 \mathrm{M}$ urea and $25^{\circ} \mathrm{C}$; $\mathrm{pH} 2.5,8 \mathrm{M}$ urea and $57^{\circ} \mathrm{C}$; pH $2.5,12.5 \%$ TFE and $25^{\circ} \mathrm{C}$.

with relatively narrow signals dispersed along the aliphatic region. At $\mathrm{pH} 2.5$ and $25^{\circ} \mathrm{C}$, the folded appearance of the nuclear magnetic resonance (NMR) spectrum remains nearly unchanged. On the other hand, at $8 M$ urea, the resonances are clustered without fine structure. Methyl groups are clustered into three groups, those corresponding to Val, Leu, and Ile at $0.8-1 \mathrm{ppm}$, those from Thr at $1.2 \mathrm{ppm}$ and from Ala at $1.4 \mathrm{ppm}$. Upon increasing the temperature to $57^{\circ} \mathrm{C}$, these peaks shifted down-field as expected. The NMR spectrum of $\alpha$-chymotrypsin at acidic $\mathrm{pH}$ and high temperature (Condition I) was found to represent an unfolded protein structure. ${ }^{30}$ On the other hand, the spectrum of $\alpha$-chymotrypsin in $12.5 \%$ TFE, $\mathrm{pH} 2.5$ (Condition II) revealed a marked difference when compared with that of the unfolded protein at the same temperature. Although the methyl proton signals of $\alpha$-chymotrypsin at $8 \mathrm{M}$ urea and $25^{\circ} \mathrm{C}$ were strongly clustered showing a characteristic double peak at 0.8-1 ppm (corresponding to Val, Leu, Ile), the signals were more dispersed in the presence of $12.5 \%$ TFE. This finding, together with CD data (see below), suggests that $\alpha$-chymotrypsin is not fully unfolded in Condition II. In addition, increased signal broadening was observed, in agreement with the oligomeric properties of $\alpha$-chymotrypsin in Condition II.

Figure 7 displays the far-UV CD spectra of $\alpha$-chymotryp$\sin$ in various conditions. In the native state, we observed two negative peaks at 230 and $202 \mathrm{~nm}$, consistent with the $\beta$ barrel structure of $\alpha$-chymotrypsin. The calculated secondary structure constituted 13\% $\alpha$-helix, 36\% $\beta$-strand, 19\% $\beta$ turn, and $32 \%$ random coil. Upon lowering the $\mathrm{pH}$ to 2.5 , the far-UV CD spectrum remained largely unchanged. In 


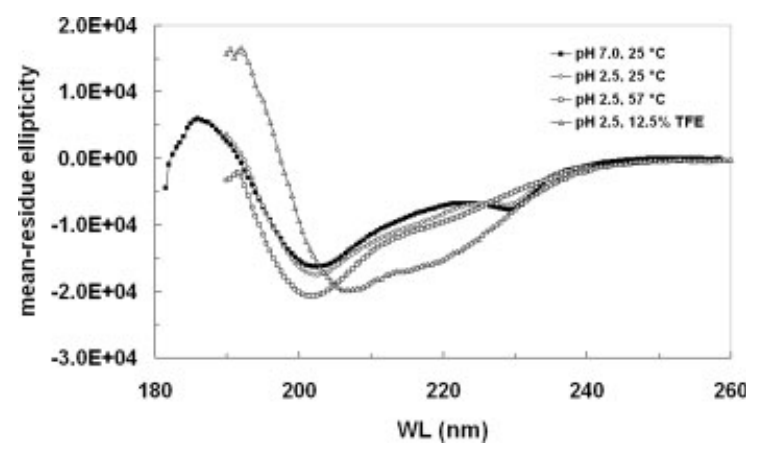

FIGURE 7 Far-UV CD spectra of $\alpha$-chymotrypsin, 5 min after subjecting the protein to various conditions. The unit of the $y$-axis is degree $\mathrm{cm}^{2} \mathrm{dmol}^{-1}$.

contrast, for the protein subjected to Condition I ( $\mathrm{pH} \mathrm{2.5,}$ $57^{\circ} \mathrm{C}$ ), the $\mathrm{CD}$ spectrum resembles that expected for a random coil, with loss of the 230 -nm peak, and a negative peak at $202 \mathrm{~nm}$. The random coil and $\beta$-turn content increased to 38 and $26 \%$, respectively, whereas those of $\alpha$-helix and $\beta$ strand dropped to 9 and $27 \%$. In Condition II, on the other hand, the CD spectrum showed two peaks at 208 and 222 $\mathrm{nm}$ that are characteristic for the formation of $\alpha$-helical structure. The estimated $\alpha$-helical content was $25 \%$. However, after $48 \mathrm{~h}$ of incubation in Conditions I and II, CD spectral characteristics of an extended intermolecular $\beta$ conformation were observed, indicative of the formation of amyloid fibrils (see Figure 4).

\section{DISCUSSION}

\section{Amyloid Versus Amorphous Aggregation}

According to results provided by Congo red absorbance, ThT fluorescence, far-UV CD spectra, and TEM images, $\alpha$-chymotrypsin was driven toward amyloid-like fibril formation by a combination of acidic $\mathrm{pH}$ and either high temperature or low TFE concentration. The extent of accompanying amorphous aggregation was low, as indicated by lack of turbidity in the range of 350-700 $\mathrm{nm}$. In contrary, when the medium $\mathrm{pH}$ was $7.0, \alpha$-chymotrypsin manifested a high tendency to form large amorphous aggregates upon heating or addition of TFE at intermediate concentrations (see Table II). ${ }^{22,23,31}$ The fibrillar aggregation propensity of $\alpha$-chymotrypsin, calculated by Zyggregator ${ }^{32}$ showed a decrease from -1.71 to -2.74 in log scale, which must be caused by the high positive net charge of the protein molecule at $\mathrm{pH} 2.5 .^{31}$ It appears that, with a slower rate of amorphous aggregation at acidic $\mathrm{pH}$, the denatured protein is provided with sufficient time to form ordered fibrillar structure, during which several steps of attachment-detachment may occur before the protein molecule finds its correct orientation. In addition, the acidic $\mathrm{pH}$ causes neutralization of the acidic residues in the aggregation-prone regions. ${ }^{33}$ Indeed, some of the "hot spot" regions of $\alpha$-chymotrypsin aggregation predicted by AGGRESCAN, ${ }^{34,35}$ ZYGGREGATOR, ${ }^{32}$ and PASTA, ${ }^{36}$ contain negatively charged residues at neutral $\mathrm{pH}$, thus their neutralization at $\mathrm{pH} 2.5$ may render them susceptible to aggregation.

\section{Fibril Formation Is Initiated from Different Conformational States}

According to dynamic quenching, ${ }^{1} \mathrm{H}-\mathrm{NMR}$, far-UV CD, and DLS, the starting conformation of $\alpha$-chymotrypsin in Condition I ( $\left.\mathrm{pH} 2.5,57^{\circ} \mathrm{C}\right)$ is an unfolded monomer. This is in agreement with results obtained by differential scanning calorimetry, which indicated that the enthalpy increase observed in high-temperature denaturation originates from complete unfolding of $\alpha$-chymotrypsin. ${ }^{37}$ In contrast, the fluorescence anisotropy, ${ }^{1} \mathrm{H}-\mathrm{NMR}$, far-UV CD, and DLS data strongly suggest that $\alpha$-chymotrypsin adopts an $\alpha$-helical rich oligomeric state in Condition II (pH 2.5, 12.5\% TFE). Despite the marked difference in the structure and assembly state, $\alpha$-chymotrypsin forms amyloid fibrils in both conditions. Amyloid fibril formation in the two conditions is probably favored by the common features of the two conformational states, including a greater exposure of hydrophobic and aromatic residues (indicated by tryptophan and ANS emission spectral changes and dynamic quenching data), as well as a high negative charge (about -15) that prevents the competing amorphous aggregation. As proposed by several studies, ${ }^{38-40}$ hydrophobic and $\pi$-stacking interactions are important for stabilization of intermolecular $\beta$-sheets in amyloid fibrils. Taken together, these data indicate that a specific conformation is not required to form amyloid fibrils, and the aggregation process could start from conformations with various secondary and tertiary structural characteristics, provided that the solution condition allows formation of intermolecular interactions and inhibits the alternative pathway of amorphous aggregation. This suggests that the amyloid fibrillar state of a protein is accessible to a variety of structurally distinct conformational ensembles. As a result, protein evolution and cellular mechanisms that avoid amyloid fibrillation of diverse non-native conformations are considered to be of paramount importance. ${ }^{41}$

Amyloid aggregation often involves the interaction between solvent-exposed and flexible regions that lack stable hydrogen-bonded elements of secondary structure, but that can readily form intermolecular $\beta$-sheet structure. ${ }^{12}$ Previous studies have shown that partially folded states containing $\alpha$ helical structures are highly populated under conditions in which amyloid formation occurs, ${ }^{42-44}$ suggesting that the 
Table II Extent of Amorphous and Amyloid Aggregation of $\alpha$-Chymotrypsin at Various Experimental Conditions, Evaluated at the End of a 48-h Incubation Period

\begin{tabular}{ccccc}
\hline Temperature $\left({ }^{\circ} \mathrm{C}\right)$ & $\mathrm{pH}$ & TFE Concentration $(\mathrm{v} / \mathrm{v} \%)$ & Amorphous Aggregation $^{\text {a }}$ & Amyloid Aggregation $^{\text {a }}$ \\
\hline 25 & 7.0 & 0 & - & - \\
& & $12.5-40$ & -+ & - \\
& $>40$ & - & - & - \\
++ & - & - \\
57 & $10-15$ & ++ & ++ \\
\hline
\end{tabular}

a The extent of amorphous and amyloid aggregation was assessed by 350-nm turbidity and ThT fluorescence emission intensity of the sample solutions, respectively. For the amyloid aggregation, gentle agitation was applied.

initial $\alpha$-helix formation does not necessarily impede intermolecular interactions and self-association. TFE is known to stabilize hydrogen bonds and weaken hydrophobic interactions, ${ }^{45}$ and was used previously to induce amyloid aggregation. $^{22,23,46} \alpha$-Chymotrypsin retains its folded structure at very low TFE concentrations (up to $10 \%$ at $\mathrm{pH} 7$ ), but at higher concentrations of TFE, a partially unfolded ensemble of conformations with increasing ratio of $\alpha$-helical/disordered structures is induced. ${ }^{23}$ The optimal TFE concentration for amyloid fibril formation by $\alpha$-chymotrypsin at acidic $\mathrm{pH}$ was $12.5 \%$ (Table II), where it is expected that the formation of intermolecular $\mathrm{H}$-bonds is sufficiently favored by TFE, but the intramolecular $\alpha$-helical content is not sufficiently high to inhibit the intermolecular interactions, as it is the case at higher TFE concentrations.

\section{TFE-Induced $\alpha$-Helical Rich Oligomers}

Our data suggest that low concentrations of TFE at acidic $\mathrm{pH}$ may induce an $\alpha$-helical rich oligomeric state of $\alpha$-chymotrypsin that transforms gradually to $\beta$-sheet-containing amyloid fibrils. There is increasing evidence that the most toxic species in the pathogenesis of neurodegenerative diseases like Alzheimer's and Parkinson's diseases are aggregation intermediates, soluble oligomeric species, and not the amyloid fibrils itself. ${ }^{47}$ Although it is not possible to address with the current data whether the oligomers observed in Condition II are on- or off-pathway, we suggest that the characterization of these model oligomers in structural, functional, and biological terms may shed light on the mechanism of toxicity of soluble oligomers in neurodegenerative diseases.

\section{Amyloid Fibrils Obtained in Different Aggregation-Promoting Conditions}

Although our data unambiguously show that the structural features of the soluble states that precede aggregation are different, the essential nature of the resulting amyloid-like aggregates (fibrillar morphology with diameters of about 10$12 \mathrm{~nm}$, extensive $\beta$-structure, and ThT and Congo red binding) is similar in both of the studied conditions. The regions of a polypeptide sequence involved in triggering the aggregation process are, in general, likely to be those that are relatively flexible and not involved in strong intramolecular interactions. ${ }^{12}$ Since different solution conditions may cause different regions to have such characteristics, the core of amyloid fibrils could well differ significantly and lead to the structural diversity of the resulting assemblies, as reported earlier. ${ }^{48-50}$ It is unclear with the current data if the observed similarity in the gross features of $\alpha$-chymotrypsin fibrils extends to more detailed structural levels. This requires the structural characterization of the two types of fibrils through a combination of high-resolution methods (including solidstate NMR, H/D exchange, and spin-labeled electron paramagnetic resonance) and intermediate-resolution ones (like atomic force microscopy and cryo-electron microscopy), and could reveal how different aggregation conditions affect the structures and stability of amyloid fibrils.

In conclusion, the $\beta$-barrel protein $\alpha$-chymotrypsin was driven toward amyloid-like fibril formation through two different conditions that induce two very different conformations preceding amyloid formation: a fully unfolded monomeric state and an $\alpha$-helical-rich oligomeric species. Based on the observations outlined in the present communication, and those reported earlier, it is suggested that diverse unfolded conformations of $\alpha$-chymotrypsin may be prone to amyloid aggregation upon inhibition of the events leading to formation of amorphous aggregates. The accessibility of the amyloid state from a variety of structurally distinct conformational ensembles highlights the critical importance of protein evolution mechanism to prevent protein misfolding. 


\section{MATERIALS AND METHODS}

$\alpha$-Chymotrypsin, 2,2,2, TFE, thioflavin-T (ThT), Congo red, urea, and phenylmethylsulfonyl fluoride (PMSF) were purchased from Sigma (St. Louis, MO). ANS was obtained from Merck (Darmstadt, Germany).

\section{Induction of Amyloid Aggregation}

To drive $\alpha$-chymotrypsin toward amyloid aggregation, two different methods were employed. In both methods, the protein concentration was $2 \mathrm{mg} / \mathrm{mL}$ and glycine $(10 \mathrm{mM}$, pH 2.5) was used as buffer, while the temperature was kept constant by the use of a flow heater. The first method consisted of incubating the protein solution at $57^{\circ} \mathrm{C}$ for the specified times, while the sample was gently agitated with fine Teflon magnetic bars. In the second procedure, the fluorinated alcohol TFE was added at a final concentration of $12.5 \%(\mathrm{v} / \mathrm{v})$ and the resultant protein solution was incubated at $25^{\circ} \mathrm{C}$ with fine agitation.

\section{Dye Binding Assays}

Thioflavin-T binding assays were performed using $15-\mu \mathrm{L}$ aliquots drawn from $2 \mathrm{mg} / \mathrm{mL} \alpha$-chymotrypsin samples preincubated as indicated above. These aliquots were diluted into a buffer $(10 \mathrm{mM}$ sodium phosphate, $150 \mathrm{mM} \mathrm{NaCl}, \mathrm{pH} 7.0)$ containing $65 \mu M$ ThT, and adjusted to a final volume of $600 \mu \mathrm{L}$. Fluorescence emission spectra were recorded before, and $3 \mathrm{~min}$ after addition of protein aliquots. The excitation wavelength was fixed at $440 \mathrm{~nm}$, with excitation and emission slit widths of 5 and $10 \mathrm{~nm}$, respectively. Fluorescence experiments were carried out on a Cary Eclipse VARIAN fluorescence spectrophotometer at $25^{\circ} \mathrm{C}$, with temperature controlled within $\pm 0.1^{\circ} \mathrm{C}$ by a Cary temperature controller.

Congo red binding assays were carried out with $10-\mu \mathrm{L}$ aliquots drawn from the above-mentioned $\alpha$-chymotrypsin samples, which were added to $1000-\mu \mathrm{L}$ volumes of the buffer ( $5 \mathrm{mM}$ potassium phosphate, $150 \mathrm{mM} \mathrm{NaCl}, \mathrm{pH}$ 7.4) containing $50 \mu \mathrm{M}$ Congo red. Absorbance spectra were recorded between 400 and $700 \mathrm{~nm}$, before and $30 \mathrm{~min}$ after addition of protein aliquots, according to a procedure described earlier, ${ }^{28}$ and using a UV-160 Shimadzu spectrophotometer.

\section{TEM}

Ten-microliter aliquots of the preincubated $\alpha$-chymotrypsin samples were placed on 400-mesh carbon-coated copper grids, and allowed to stand for $2 \mathrm{~min}$. Then, excess fluid was drawn out using a paper filter, and $1 \%$ uranyl acetate was added. Again after another 2 min, excess dye was removed. Finally, the grids were viewed using a CEM 902A ZEISS microscope.

\section{Fluorescence Spectroscopy}

Fluorescence experiments were performed on a Cary Eclipse VARIAN spectrofluorimeter, with temperature controlled within $\pm 0.1^{\circ} \mathrm{C}$ by a Cary temperature controller. The intrinsic emission spectra were obtained at a protein concentration of $4 \mu M(0.1 \mathrm{mg} / \mathrm{mL})$. The excitation wavelengths were 280 and $295 \mathrm{~nm}$, and the excitation and emission slit widths were fixed at $5 \mathrm{~nm}$. The polarity-sensitive probe ANS was used to investigate the nature of conformational states promoted by the acidic $\mathrm{pH}$ and high temperature, or $12.5 \%$ TFE. Fluorescence emission spectra of ANS were taken at an ANS concentration of $20 \mathrm{mM}$ and $\alpha$-chymotrypsin concentration of about $0.05 \mathrm{mg} / \mathrm{mL}$, in experimental conditions suitable for amyloid induction (Methods I and II). The changes in ANS emission spectra were followed at $1 \mathrm{~min}$ intervals for $1 \mathrm{~h}$. Excitation wavelength was $365 \mathrm{~nm}$, and excitation and emission slit widths were 5 and $10 \mathrm{~nm}$, respectively.

Fluorescence quenching was analyzed according to the SternVolmer relationship $\left(F_{0} / F=1+K_{\mathrm{SV}}[Q]\right)$, where $F_{0}$ is the fluorescence in the absence of quencher, $F$ is the fluorescence at molar quencher (acrylamide) concentration $[Q]$, and $K_{\mathrm{SV}}$ is the SternVolmer constant obtained from the slope of a plot of $F_{0} / F$ versus [Q]. The excitation wavelength was $295 \mathrm{~nm}$ (with 5-nm slit width), and the wavelength of maximal emission intensity was employed for the analysis. Acrylamide concentrations ranged from 0 to $0.15 \mathrm{M}$.

Steady-state fluorescence anisotropy, $r$, was measured using the L-format method incorporating G-factor corrections. The excitation and emission wavelengths were 295 and $340 \mathrm{~nm}$, with slit widths of $5 \mathrm{~nm}$. The measured G-factor was 0.9549 .

\section{Spectroscopy}

CD spectra in the far-UV region (190-260 nm) were obtained on a JASCO 810 spectrometer, using 1-mm path cell and a protein concentration of $8 \mu M(0.2 \mathrm{mg} / \mathrm{mL})$ at $25^{\circ} \mathrm{C}$. The temperature was controlled within $\pm 0.1^{\circ} \mathrm{C}$ by a PolyScience recirculating chiller. Protein secondary structure was determined by the program $\mathrm{CDNN}$, version 2.1.0.223, using a network trained with 33 complex spectra as the reference set.

\section{Dynamic Light Scattering}

DLS experiments were performed at the relevant temperatures without stirring, on a DynaPro Titan (Wyatt Technology Corp., CA) instrument, with a laser of $827.08 \mathrm{~nm}$ and a scattering angle of $90^{\circ}$. The protein solution was filtered through a Microcon- 100 centrifugal device at $12,000 \mathrm{~g}$ for $15 \mathrm{~min}$. The final protein concentration was $40 \mu \mathrm{M}$. Each DLS measurement consisted of twenty 10 s-long acquisitions. Refractive index (RI) of the solution at $589 \mathrm{~nm}$ and $20^{\circ} \mathrm{C}$ was set at $1.333,1.332$, and 1.400 , respectively for glycine (and phosphate) buffers(s), 12.5\% TFE, and $8 M$ urea, and the RI at the studied wavelength was obtained through Cauchy equation, with a coefficient of $3119 \mathrm{~nm}^{2}$. The respective viscosities were $1.019,1.271$, and $1.663 \mathrm{cp}$ at $20^{\circ} \mathrm{C}$ and the temperature-dependent variations were calculated by an aqueous model. Diffusion coefficients were derived from the intensity autocorrelation functions, and the corresponding hydrodynamic radii were calculated through Stokes-Einstein formula. The DLS experiments were performed at least in triplicates.

\section{NMR Spectroscopy}

${ }^{1} \mathrm{H}$ NMR experiments were carried out in a Bruker $400 \mathrm{MHz}$ spectrometer at the specified temperatures, with $16 \mathrm{~K}$ data points and using presaturation to eliminate the water signals. In all cases, 256 scans were acquired and the spectral width was $6400 \mathrm{~Hz}$. The NMR samples contained $20 \mu \mathrm{M}(0.5 \mathrm{mg} / \mathrm{mL})$ of chymotrypsin in $90 \%$ water $/ 10 \% \mathrm{D}_{2} \mathrm{O}$. To selectively excite the methyl region, a Gaussian- 
shaped $90^{\circ}$ pulse of $380-\mathrm{Hz}$ frequency and 2.5 -ms duration was employed. Standard Bruker pulse sequences were used and the obtained data were analyzed by Topspin 2.1.

The authors thank Dr. Thomas Jovin and Dr. Reinhard Jahn for access to fluorescence and CD spectroscopy instruments.

\section{REFERENCES}

1. Westermark, P.; Benson, M. D.; Buxbaum, J. N.; Cohen, A. S.; Frangione, B.; Ikeda, S.; Masters, C. L.; Merlini, G.; Saraiva, M. J.; Sipe, J. D. Amyloid 2002, 9, 197-200.

2. Dobson, C. M. Nature 2002, 418, 729-730.

3. Merlini, G.; Bellotti, V. N Eng J Med 2003, 349, 583-596.

4. Scheibel, T.; Parthasarathy, R.; Sawicki, G.; Lin, X. M.; Jaeger, H.; Lindquist, S. L. Proc Natl Acad Sci USA 2003, 100, 45274532.

5. Hamada, D.; Yanagihara, I.; Tsumoto, K. Trends Biotechnol 2004, 22, 93-97.

6. Chiti, F.; Webster, P.; Taddei, N.; Clark, A.; Stefani, M.; Ramponi, G.; Dobson, C. M. Proc Natl Acad Sci USA 1999, 96 3590-3594.

7. Uversky, V. N.; Fink, A. L. Biochim Biophys Acta 2004, 1698, 131-153.

8. Makin, O. S.; Serpell, L. C. FEBS J 2005, 272, 5950-5961.

9. Nelson, R.; Eisenberg, D. Adv Protein Chem 2006, 73, 235-282.

10. Bemporad, F.; Calloni, G.; Campioni, S.; Plakoutsi, G.; Taddei, N.; Chiti, F. Acc Chem Res 2006, 39, 620-627.

11. Soldi, G.; Bemporad, F.; Torrassa, S.; Relini, A.; Ramazzotti, M.; Taddei, N.; Chiti, F. Biophys J 2005, 89, 4234-4244.

12. Calamai, M.; Chiti, F.; Dobson, C. M. Biophys J 2005, 89, 42014210.

13. Vernaglia, B. A.; Huang, J.; Clark, E. D. Biomacromolecules 2004, 5, 1362-1370.

14. Goda, S.; Takano, K.; Yamagata, Y.; Nagata, R.; Akutsu, H.; Maki, S.; Namba, K.; Yutani, K. Protein Sci 2000, 9, 369-375.

15. De Felice, F. G.; Vieira, M. N.; Meirelles, M. N.; MorozovaRoche, L. A.; Dobson, C. M.; Ferreira, S. T. FASEB J 2004, 18, 1099-1101.

16. Cao, A.; Hu, D.; Lai, L. Protein Sci 2004, 13, 319-324.

17. Krebs, M. R.; Wilkins, D. K.; Chung, E. W.; Pitkeathly, M. C.; Chamberlain, A. K.; Zurdo, J.; Robinson, C. V.; Dobson, C. M. J Mol Biol 2000, 300, 541-549.

18. McParland, V. J.; Kalverda, A. P.; Homans, S. W.; Radford, S. E. Nat Struct Biol 2002, 9, 326-331.

19. Ahmad, A.; Millet, I. S.; Doniach, S.; Uversky, V. N.; Fink, A. L. Biochemistry 2003, 42, 11404-11416.

20. Wright, H. T. J Mol Biol 1973, 79, 1-11.

21. Richardson, J. S.; Richardson, D. C. Proc Natl Acad Sci USA 2002, 99, 2754-2759.

22. Pallares, I.; Vendrell, J.; Aviles, F. X.; Ventura, S. J Mol Biol 2004, 342, 321-331.

23. Rezaei-Ghaleh, N.; Ebrahim-Habibi, A.; Moosavi-Movahedi, A. A.; Nemat-Gorgani, M. Arch Biochem Biophys 2007, 457, 160 169.

24. Nilsson, M. R. Methods 2004, 34, 151-160.

25. Sunde, M.; Blake, C. Adv Protein Chem 1997, 50, 123-159.
26. Harris, D. L.; Hudson, B. S. Biochemistry 1990, 29, 5276-5285.

27. Choy, W. Y.; Mulder, F. A.; Crowhurst, K. A.; Muhandiram, D. R.; Millett, I. S.; Doniach, S.; Forman-Kay, J. D.; Kay, L. E. J Mol Biol 2002, 316, 101-112.

28. Wilkins, D. K.; Grimshaw, S. B.; Receveur, V.; Dobson, C. M.; Jones, J. A.; Smith, L. J. Biochemistry 1999, 38, 16424-16431.

29. Kohn, J. E.; Millett, I. S.; Jacob, J.; Zagrovic, B.; Dillon, T. M.; Cingel, N.; Dothager, R. S.; Seifert, S.; Thiyagarajan, P.; Sosnick, T. R.; Hasan, M. Z.; Pande, V. S.; Ruczinski, I.; Doniach, S.; Plaxco, K. W. Proc Natl Acad Sci USA 2004, 101, 12491-12496.

30. Schwarzinger, S.; Kroon, G. J.; Foss, T. R.; Wright, P. E.; Dyson, H. J. J Biomol NMR 2000, 18, 43-48.

31. Rezaei-Ghaleh, N.; Ebrahim-Habibi, A.; Moosavi-Movahedi, A. A.; Nemat-Gorgani, M. Biophys Chem 2008, 132, 23-32.

32. Tartaglia, G. G.; Vendruscolo, M. Chem Soc Rev 2008, 37, 1395-1401.

33. Picotti, P.; De Franceschi, G.; Frare, E.; Spolaore, B.; Zambonin, M.; Chiti, F.; de Laureto, P. P.; Fontana, A. J Mol Biol 2007, 367, 1237-1245.

34. de Groot, N. S.; Pallares, I.; Aviles, F. X.; Vendrell, J.; Ventura, S. BMC Struct Biol 2005, 5, 18.

35. Conchillo-Sole, O.; de Groot, N. S.; Aviles, F. X.; Vendrell, J.; Daura, X.; Ventura, S. BMC Bioinformatics 2007, 8, 65.

36. Trovato, A.; Chiti, F.; Maritan, A.; Seno, F. PLoS Comput Biol 2006, 2, e170; doi:10.1371/journal.pcbi.0020170.

37. Freire, E. Methods Enzymol 1994, 240, 502-530.

38. Pawar, A. P.; Dubay, K. F.; Zurdo, J.; Chiti, F.; Vendruscolo, M.; Dobson, C. M. J Mol Biol 2005, 350, 379-392.

39. Makin, O. S.; Atkins, E.; Sikorski, P.; Johansson, J.; Serpell, L. C. Proc Natl Acad Sci USA 2005, 102, 315-320.

40. Gazit, E. FASEB J 2002, 16, 77-83.

41. Wright, C. F.; Teichmann, S. A.; Clarke, J.; Dobson, C. M. Nature 2005, 438, 878-881.

42. Kayed, R.; Bernhagen, J.; Greenfield, N.; Sweimeh, K.; Brunner, H.; Voelter, W.; Kapurniotu, A. J Mol Biol 1999, 287, 781-796.

43. Bouchard, M.; Zurdo, J.; Nettleton, E. J.; Dobson, C. M.; Robinson, C. V. Protein Sci 2000, 9, 1960-1967.

44. Kirkitadze, M. D.; Condron, M. M.; Teplow, D. B. J Mol Biol 2001, 312, 1103-1119.

45. Buck, M. Q Rev Biophys 1998, 31, 297-355.

46. Chiti, F.; Taddei, N.; Bucciantini, M.; White, P.; Ramponi, G.; Dobson, C. M. EMBO J 2000, 19, 1441-1449.

47. Hepler, R. W.; Grimm, K. M.; Nahas, D. D.; Breese, R.; Dodson, E. C.; Acton, P.; Keller, P. M.; Yeager, M.; Wang, H.; Shughrue, P.; Kinney, G.; Joyce, J. G. Biochemistry 2006, 45, 15157-15167.

48. Paravastu, A. K.; Petkova, A. T.; Tycko, R. Biophys J 2006, 90, 4618-4629.

49. Hoyer, W.; Antony, T.; Cherny, D.; Heim, G.; Jovin, T. M.; Subramaniam, V. J Mol Biol 2002, 322, 383-393.

50. Smith, D. P.; Jones, S.; Serpell, L. C.; Sunde, M.; Radford, S. E. J Mol Biol 2003, 330, 943-954.

Reviewing Editor: Alfred Wittinghofer 